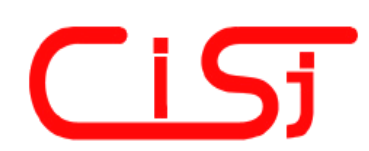

\title{
TRIANGULAR DISCRETISATION FOR ANALYSIS OF MICROSTRIP MITRED BEND, BY AN ITERATIVE METHOD USING THE FAST MODAL TRANSFORM
}

\author{
Y. Lamhene ${ }^{1)}$, M. Tellache ${ }^{1)}$, B. Haraoubia ${ }^{\text {1) }}$, H. Baudrand ${ }^{2)}$ \\ ${ }^{1)}$ Laboratoire d'Instrumentation, Faculté d'Electronique et d'Informatique \\ Université U.S.T.H.B. B.P 32 El Alia Bab-Ezzouar 16111 Alger, \\ e-mail: youcef_lamhene@yahoo.fr, haroubiab@yahoo.fr, tellachemoh@yahoo.fr \\ ${ }^{2)}$ Laboratoire d'Electronique, INP, ENSEEIHT, 2, Rue Charles Camichel \\ 31071 Toulouse Cedex, e-mail: henry.baudrand@yahoo.fr
}

\begin{abstract}
In this paper, a study based on iterative method is presented. This method consists in generating a recursive relationship between a wave source and reflected waves from the discontinuity plane which is divided into cells. A high computational speed has been achieved by using Fast Modal Transform (FMT). This work is followed by an application of triangular discretization which offers several advantages over rectangular discretization. The right bend can be simulated by both rectangular and triangular cells, while the mitred bend can be exactly conformed only by the triangular mesh. Deficiencies in the rectangular approximation are identified. The computed results have been successfully compared with published data.
\end{abstract}

Keywords: Planar microwave circuit, mitred bend, triangular discretization, Fast Modal Transform.

\section{INTRODUCTION}

Methods based on an integral formulation [1] seem to be accurate and rigorous tools for the treatment of different planar structures (Tee, Gap, Bend, Step...)

Among these methods we can distinguish methods lying in an iterative process which resolve an eigenvalue problem, and other which, by the introduction of an excitation source, reduce the equations into an inhomogeneous system via the application of the method of moments. Moreover, the integral methods [2]-[3] become efficient if basis functions have been correctly chosen.

We have developed an iterative method based on the wave concept [4-]-[5]-[6], where choice of bases functions does not arise any more.

This principle gives originality in this method. It requires, only with the precondition, a simple convergence test of the computed impedance viewed by the source.

As shown in figure 1, the planar structure, placed in a metallic box (spectral domain) is divided into cells (spatial domain) and includes three subdomains: Source, Metal and Dielectric. This concept consists in successive reflections between the circuit plane and its two sides (upper and low metallic box).
It also has alternative behaviour between space and spectral domain. This technique is combined with the Fast Modal Transform (FMT) deduced from the classic FFT (Fast Fourier Transform). Consequently a high computational speed can be achieved.

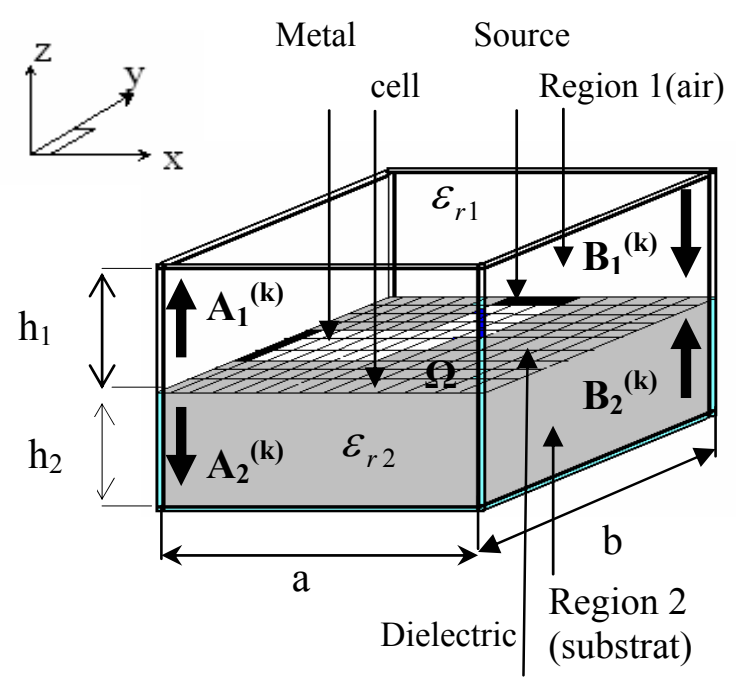

Fig. 1 - Approximate mitred bend (rectangular cells) 
This method is applied to simulate microstrip corner and mitred bend using rectangular and triangular discretization.

The triangles conform exactly to any angled shapes in the discontinuity, and curved forms are reproduced in a line-segment rather than stair-case approximation using rectangular cells. In this simulation, by computing the $\mathrm{S}$ parameters, we show deficiencies in rectangular approximation for the mitred bend, so efficient solution requires efficient computation.

\section{THEORETICAL DEVELOPMENTS}

\subsection{PRINCIPLE}

The implementation of the iterative process consists of establishing a recursive for the relationship between the waves in the two regions 1 and 2, using the reflection in spectral domain (equation 1) and the diffraction (with boundary conditions required on $\Omega$ ) in the spatial domain (equation 2).

The governing equations employed are:

$$
\begin{aligned}
& B_{i}^{(k)}=€_{A_{i}{ }^{(k-1)}} \\
& A_{i}^{(k)}=\bigoplus_{\text {int }} B_{i}^{(k)}+A_{i}^{(0)}
\end{aligned}
$$

$k:$ is the iteration number

$B i:$ is the reflected wave on region 1 or 2 .

$f:$ is a reflection operator in the spectral domain.

$A i$ : is the incidental wave on region 1 or 2 .

$\xi_{\text {int }}$ : is a diffraction operator on the discontinuity plane $\Omega$ in the space domain.

$\mathrm{A}_{i}^{(0)}=\frac{\overrightarrow{\mathrm{E}}_{0}}{\sqrt{\mathrm{Z}_{0 i}}}:$ is the source wave (initial wave).

$\overrightarrow{\mathrm{E}}_{0}$ : is the electric field produced by the source.

$Z_{0 i}$ : is the intrinsic impedance of region 1 or 2 .

In the equation (2), Bi becomes incidental wave and $A i$ the reflected one.

The iterative process is given in figure 2 , for one iteration.

It uses the FMT (Fast Modal Transform) deduced from the FFT (Fast Fourier Transform) which makes it possible to accelerate the digital processing on the whole of the pixels of the planar considered circuit.

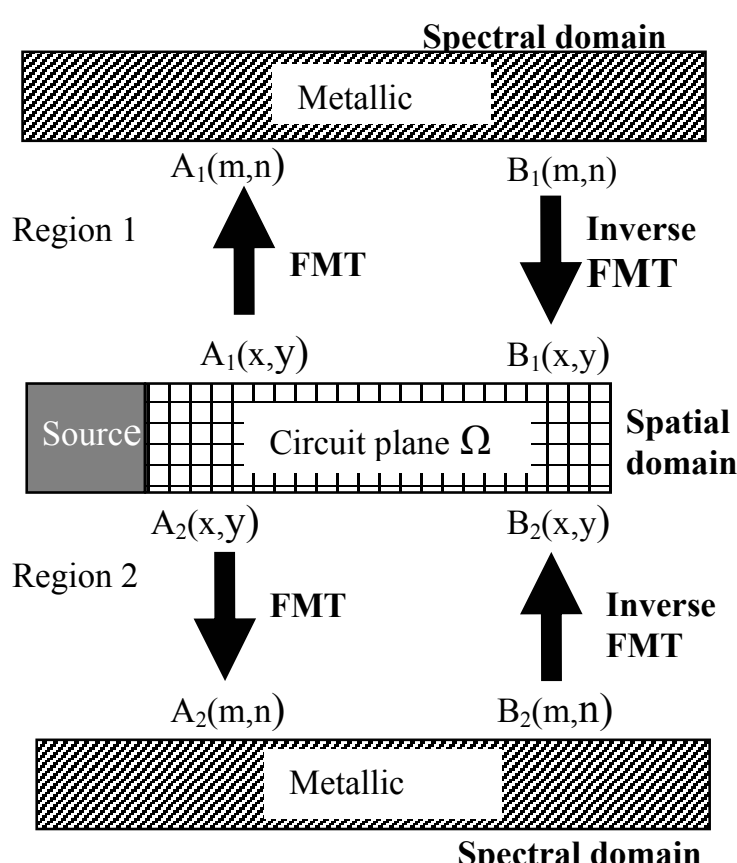

Fig. 2 - Fast Modal Transform for one iteration

\subsection{REFLECTION IN THE SPECTRAL DOMAIN}

The reflection operator is expressed as:

$$
€=\frac{1-Z_{0 i} £}{1+Z_{0 i}^{£}}
$$

F is the operator admittance

It uses the bases functions $\left|f_{m n}^{\alpha}\right\rangle$ of the box modes as follows:

$$
\notin=\sum_{m, n}\left|f_{m n}^{\alpha}\right\rangle \mathrm{Y}_{m n}^{\alpha}\left\langle f_{m n}^{\alpha}\right|
$$

$\alpha$ is the TE or TM mode.

$f$ can be expressed in another manner according to the formalism of the mathematical operators [7]:

$$
\begin{gathered}
€=\sum_{m, n}\left|f_{m n}^{T E}\right\rangle \Gamma_{m n}^{T E}\left\langle f_{m n}^{T E}\right|+ \\
\sum_{m, n}\left|f_{m n}^{T M}\right\rangle \Gamma_{m n}^{T M}\left\langle f_{m n}^{T M}\right|
\end{gathered}
$$

\subsection{REFLECTION AND DIFFRACTION IN THE SPACE DOMAIN}

The wave concept is introduced by writing the electric field $\mathrm{Ei}$ and the current density $\mathrm{J}_{\mathrm{i}}$ in terms of waves.

It leads to the following set of equations [5] 


$$
\begin{aligned}
& \overrightarrow{\mathrm{E}}_{i}=\sqrt{\mathrm{Z}_{0 i}}\left[\overrightarrow{\mathrm{A}}_{i}+\overrightarrow{\mathrm{B}}_{i}\right] \\
& \vec{J}_{i}=\frac{1}{\sqrt{\mathrm{Z}_{0 i}}}\left[\overrightarrow{\mathrm{A}}_{i}-\overrightarrow{\mathrm{B}}_{i}\right]
\end{aligned}
$$

Where: $\quad Z_{o i}=\sqrt{\frac{\mu_{0}}{\varepsilon_{0} \varepsilon_{r i}}}$

The diffraction operator $\S_{\text {int }}$ is defined in the space domain. It gives the boundary conditions and the relations of continuity of the tangential fields on the interface $\Omega$

The planar circuit is divided to three subdomains (metal, dielectric and source)

\subsubsection{METALLIC SUBDOMAIN}

The boundary condition on the metal can be written as:

$$
\left\{\begin{array}{l}
\overrightarrow{\mathrm{E}}_{1}=\overrightarrow{\mathrm{E}}_{2}=0 \\
\vec{J}_{1}=\vec{J}_{2}=\vec{J}_{0}
\end{array}\right.
$$

Considering calculation by wave concept, we have:

$$
\begin{aligned}
& \sqrt{\mathrm{Z}_{01}}\left(\overrightarrow{\mathrm{A}}_{1}+\overrightarrow{\mathrm{B}}_{1}\right)=\sqrt{\mathrm{Z}_{02}}\left(\overrightarrow{\mathrm{A}}_{2}+\overrightarrow{\mathrm{B}}_{2}\right)=0 \\
& \Rightarrow\left\{\begin{array}{l}
\overrightarrow{\mathrm{A}}_{1}=-\overrightarrow{\mathrm{B}}_{1} \\
\overrightarrow{\mathrm{A}}_{2}=-\overrightarrow{\mathrm{B}}_{2}
\end{array}\right.
\end{aligned}
$$

These two relations can be introduced in the following matrix form as:

$$
\left[\begin{array}{l}
\vec{A}_{1} \\
\vec{A}_{2}
\end{array}\right]=\left(\begin{array}{lll}
-\mathrm{H} & m & 0 \\
0 & -\mathrm{H}_{m}
\end{array}\right)\left(\begin{array}{l}
\overrightarrow{\mathrm{B}}_{1} \\
\overrightarrow{\mathrm{B}}_{2}
\end{array}\right)
$$

Where $\mathrm{H}_{\mathrm{m}}$ is the indicating function of the metal region which is defined as:

$$
\begin{aligned}
\mathrm{H}_{\mathrm{m}} & = \begin{cases}1 & \text { on the metal } \\
0 & \text { elsewhere }\end{cases} \\
\Rightarrow \quad \oiint_{\text {int } m} & =\left[\begin{array}{cc}
-H_{m} & 0 \\
0 & -H_{m}
\end{array}\right]
\end{aligned}
$$

The waves are completely reflected by metal. Thus: $£_{\text {int } \text { metal }}=-1$

\subsubsection{DIELECTRIC SUBDOMAIN}

The boundary and the continuity conditions on the dielectric are:

$$
\left\{\begin{array}{l}
\vec{J}_{1}+\vec{J}_{2}=0 \\
\overrightarrow{\mathrm{E}}_{1}=\overrightarrow{\mathrm{E}}_{2} \neq 0
\end{array}\right.
$$

Considering the waves, we have:

$$
\left[\begin{array}{l}
\overrightarrow{\mathrm{A}}_{1} \\
\overrightarrow{\mathrm{A}}_{2}
\end{array}\right]=\left[\begin{array}{ll}
\frac{1-\mathrm{N}^{2}}{1+\mathrm{N}^{2}} \mathrm{H}_{i} & \frac{2 \mathrm{~N}}{1+\mathrm{N}^{2}} \mathrm{H}_{i} \\
\frac{2 \mathrm{~N}}{1+\mathrm{N}^{2}} \mathrm{H}_{i} & -\frac{1-\mathrm{N}^{2}}{1+\mathrm{N}^{2}} \mathrm{H}_{i}
\end{array}\right]\left[\begin{array}{l}
\overrightarrow{\mathrm{B}}_{1} \\
\overrightarrow{\mathrm{B}}_{2}
\end{array}\right]
$$

Where $N$ is: $\quad N=\sqrt{\frac{Z_{01}}{Z_{02}}}$

$\mathrm{Hi}$ is the indicating function of the dielectric such as:

$$
\mathrm{Hi}= \begin{cases}1 & \text { on the dielectric } \\ 0 & \text { elsewhere }\end{cases}
$$

We deduce the diffraction operator $\S_{\text {int }}$ in this subdomain:

$$
\xi_{\text {int } d}=\left[\begin{array}{cc}
\frac{1-\mathrm{N}^{2}}{1+\mathrm{N}^{2}} \mathrm{H}_{i} & \frac{2 \mathrm{~N}}{1+\mathrm{N}^{2}} \mathrm{H}_{i} \\
\frac{2 \mathrm{~N}}{1+\mathrm{N}^{2}} \mathrm{H}_{i} & -\frac{1-\mathrm{N}^{2}}{1+\mathrm{N}^{2}} \mathrm{H}_{i}
\end{array}\right]
$$

\subsubsection{SOURCE DOMAIN}

In the iterative method, we use a cell source for exciting a planar circuit. In the figure 3 , we show a cell source obtained by a classic source of tension.

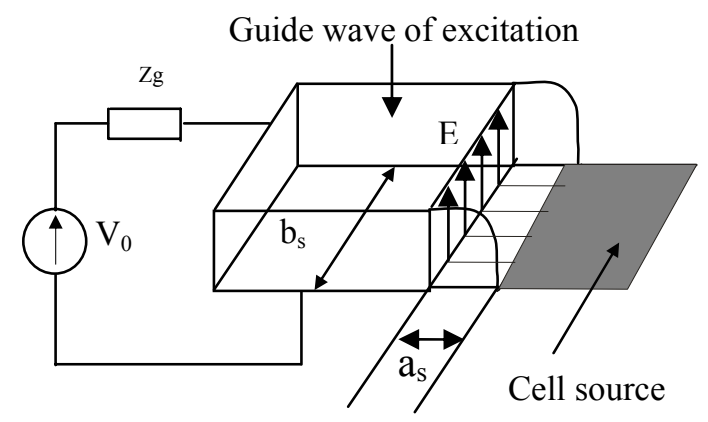

Fig. 3 - Planar source

The source emits energy through surface:

$$
S_{s}=a_{s} b_{s}
$$

This energy is guided in a waveguide and the source takes its energy of an external source of power with potential $V_{0}$ and internal impedance $Z_{g}$

The equivalent diagram of such a source (excitation from the region 1) is given in figure 4.

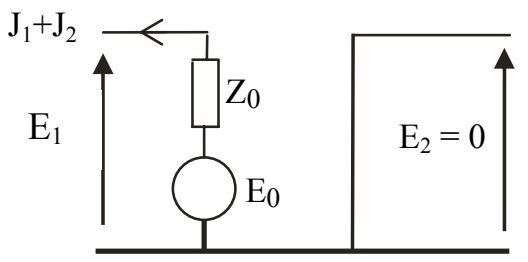

Fig. 4 - Source equivalent diagram 
The boundary condition can be written as:

$$
\left\{\begin{array}{l}
\overrightarrow{\mathrm{E}}_{1}=\overrightarrow{\mathrm{E}}_{0}-\mathrm{Z}_{0}\left(\vec{J}_{1}+\vec{J}_{2}\right) \\
\overrightarrow{\mathrm{E}}_{2}=0=\sqrt{\mathrm{Z}_{02}}\left(\overrightarrow{\mathrm{A}}_{2}+\overrightarrow{\mathrm{B}}_{2}\right) \Rightarrow \overrightarrow{\mathrm{A}}_{2}=-\overrightarrow{\mathrm{B}}_{2}
\end{array}\right.
$$

Thus, the reflected waves in the two regions can be obtained:

$$
\begin{gathered}
{\left[\begin{array}{l}
\overrightarrow{\mathrm{A}}_{1} \\
\overrightarrow{\mathrm{A}}_{2}
\end{array}\right]=\frac{1}{n_{1}+1}\left[\begin{array}{rr}
n_{1}-1 & \frac{2 \mathrm{Z}_{0}}{\sqrt{\mathrm{Z}_{01} \mathrm{Z}_{02}}} \\
-\left(n_{1}+1\right)
\end{array}\right]\left[\begin{array}{l}
\overrightarrow{\mathrm{B}}_{1} \\
\overrightarrow{\mathrm{B}}_{2}
\end{array}\right]+\frac{1}{n_{1}+1}\left[\begin{array}{l}
\frac{\mathrm{E}_{0}}{\sqrt{\mathrm{Z}_{01}}} \\
0
\end{array}\right]} \\
\text { With: } \quad n_{1}=\frac{Z_{0}}{Z_{01}}
\end{gathered}
$$

$\mathrm{Z} 0$ : is the characteristic impedance.

Finally:

$$
\S_{\text {int.S }}=\frac{1}{n_{1}+1}\left[\begin{array}{cc}
n_{1}-1 & \frac{2 Z_{0}}{\sqrt{Z_{01} Z_{02}}} \\
0 & -\left(n_{1}+1\right)
\end{array}\right]
$$

In conclusion, the computation of the waves reflected by the discontinuity plane $\Omega$ of the structure for the three subdomains is given by the equation:

$$
\left[\begin{array}{l}
A_{1} \\
A_{2}
\end{array}\right]=\left[\xi_{\text {int. } m}+\xi_{\text {int.d }}+\xi_{\text {int.s }}\right]\left[\begin{array}{l}
B_{1} \\
B_{2}
\end{array}\right]+\left[\begin{array}{l}
A_{01} H_{S} \\
A_{02} H_{s}
\end{array}\right]
$$

$\mathrm{Hs}$ : is the indicating function of the source domain:

$$
H_{s}= \begin{cases}1 & \text { on the sources } \\ 0 & \text { elsewhere }\end{cases}
$$

\section{CONTRIBUTION OF FAST FOURIER TRANSFORM}

The Fast Modal Transform procedure (figure 2) is based on the Fast Fourier Transform.

It takes into account the modes of the case (spectral domain). This transform gives the possibility to pass quickly from the $(\mathrm{x}, \mathrm{y})$ space domain to $(m, n)$ modal or spectral domain and vice versa (opposite FMT) [6]:

$$
\begin{gathered}
\vec{\Phi}(x, y) \rightarrow \vec{\Phi}(m, n) \\
\vec{Ц}(\mathrm{x}, \mathrm{y})=\sum_{m} \sum_{n} \mathrm{a}_{m n}^{T E} \overrightarrow{\mathrm{f}}_{m n}^{T E}(\mathrm{x}, \mathrm{y})+ \\
\sum_{m} \sum_{n} \mathrm{a}_{m n}^{T M} \overrightarrow{\mathrm{f}}_{m n}^{T M}(\mathrm{x}, \mathrm{y})
\end{gathered}
$$

$\mathrm{a}_{m n}^{T E}$ and $\mathrm{a}_{m n}^{T M}$ are the amplitudes of TE and TM modes.

$$
\begin{aligned}
& \mathrm{a}_{m n}^{T E}=\left\langle\overrightarrow{\mathrm{f}}_{m n}^{T E}(\mathrm{x}, \mathrm{y}) \mid \overrightarrow{\mathrm{L}}(\mathrm{x}, \mathrm{y})\right\rangle \\
& \mathrm{a}_{m n}^{T M}=\left\langle\overrightarrow{\mathrm{f}}_{m n}^{T M}(\mathrm{x}, \mathrm{y}) \mid \overrightarrow{\mathrm{L}}(\mathrm{x}, \mathrm{y})\right\rangle
\end{aligned}
$$

\section{PASSAGE FROM RECTANGULAR TO TRIANGULAR CELLS}

The software of triangular cells is deduced from the program of the rectangular cells (used for the right bend and the approximated bend).

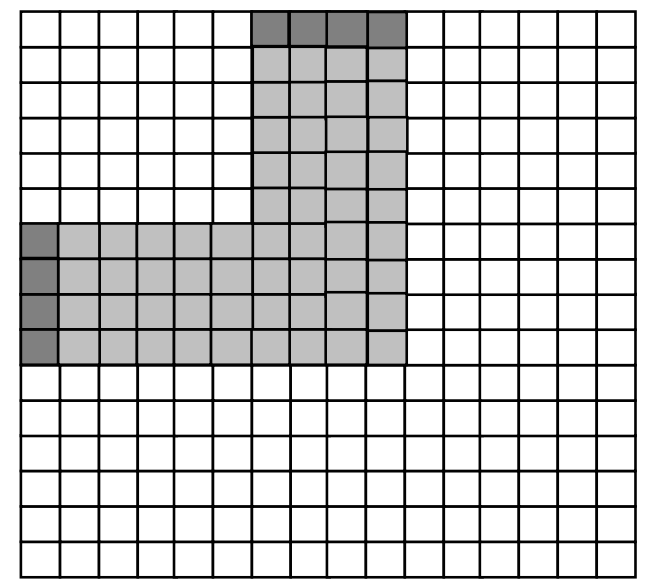

Fig. 5 - Right bend

It is necessary to use this modified software for the planar circuits having geometrical forms adapted to these cells.

Indeed, each rectangular cell gives us two triangular cells having the same surface, but different position of the centre of gravity. They are also two types of triangular cells differentiated by their slope which is positive or negative.

For the discretization of a zone of the circuit, the program requires to choose between the cell with positive or negative slope and surface in a number of cells in the two grids (positive grid or negative).

Thus, for any grid, the cells of the plane circuit are codified:

0 : for "dielectric" cells

1 : for "metal" cells

2: for "source" cells

An example for a grid of $16 \times 12$ triangular cells (with positive slope) is given in figure 6 . 


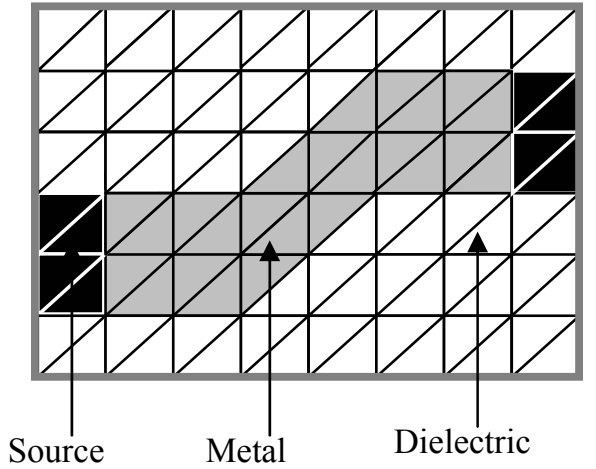

Fig. 6 - Triangular cells with positive slope

The corresponding coded grid is:

$\begin{array}{llllllllllllllll}0 & 0 & 0 & 0 & 0 & 0 & 0 & 0 & 0 & 0 & 0 & 0 & 0 & 0 & 0 & 0\end{array}$

$\begin{array}{llllllllllllllll}0 & 0 & 0 & 0 & 0 & 0 & 0 & 0 & 0 & 0 & 0 & 0 & 0 & 0 & 0 & 0\end{array}$

$\begin{array}{llllllllllllllll}0 & 0 & 0 & 0 & 0 & 0 & 0 & 0 & 0 & 0 & 1 & 1 & 1 & 1 & 2 & 2\end{array}$

$\begin{array}{llllllllllllllllllllll}0 & 0 & 0 & 0 & 0 & 0 & 0 & 0 & 0 & 1 & 1 & 1 & 1 & 2 & 2\end{array}$

$\begin{array}{lllllllllllllllll}0 & 0 & 0 & 0 & 0 & 0 & 0 & 0 & 1 & 1 & 1 & 1 & 1 & 1 & 2 & 2\end{array}$

$\begin{array}{lllllllllllllllll}0 & 0 & 0 & 0 & 0 & 0 & 0 & 1 & 1 & 1 & 1 & 1 & 1 & 1 & 2 & 2\end{array}$

$\begin{array}{llllllllllllllllllll}2 & 2 & 1 & 1 & 1 & 1 & 1 & 1 & 1 & 1 & 0 & 0 & 0 & 0 & 0 & 0\end{array}$

$\begin{array}{lllllllllllllllll}2 & 2 & 1 & 1 & 1 & 1 & 1 & 1 & 1 & 0 & 0 & 0 & 0 & 0 & 0 & 0\end{array}$

$\begin{array}{llllllllllllllll}2 & 2 & 1 & 1 & 1 & 1 & 1 & 1 & 0 & 0 & 0 & 0 & 0 & 0 & 0 & 0\end{array}$

$\begin{array}{lllllllllllllllll}2 & 2 & 1 & 1 & 1 & 1 & 1 & 0 & 0 & 0 & 0 & 0 & 0 & 0 & 0 & 0\end{array}$

$\begin{array}{llllllllllllllll}0 & 0 & 0 & 0 & 0 & 0 & 0 & 0 & 0 & 0 & 0 & 0 & 0 & 0 & 0 & 0\end{array}$

$\begin{array}{llllllllllllllll}0 & 0 & 0 & 0 & 0 & 0 & 0 & 0 & 0 & 0 & 0 & 0 & 0 & 0 & 0 & 0\end{array}$

Fig. 7 - Coded grid of 16x12 triangular cells

The rectangular discretization software is applied, to the approximated mitred bends (rectangular cells).

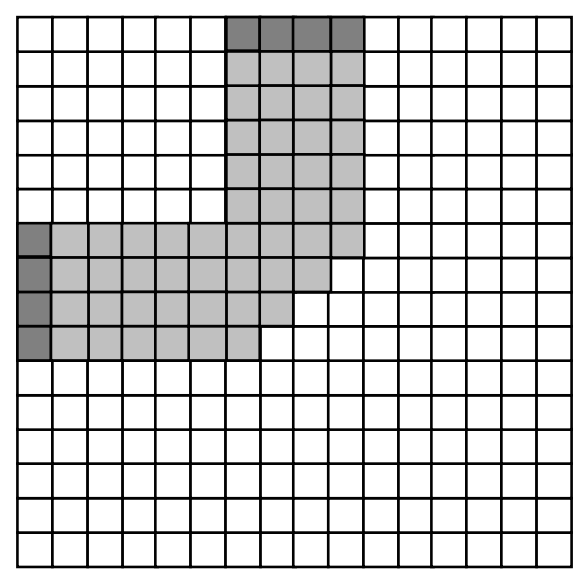

Fig. 8 - Staircase approximation mitred bend (rectangular cells)

We obtain representation with positive grid of the true mitred bend indicated by figure 9 .

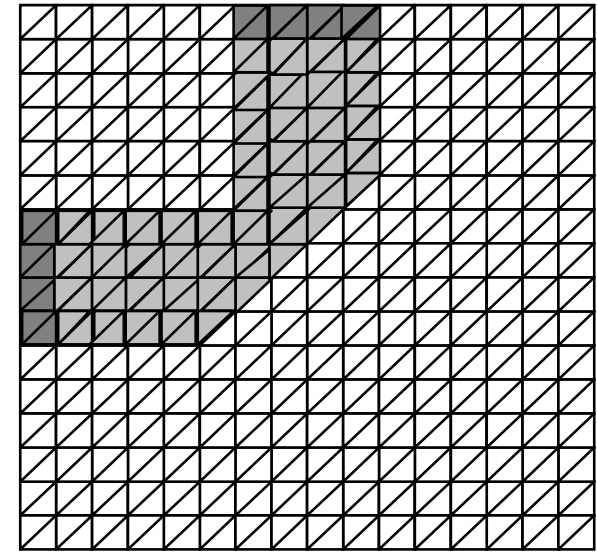

Fig. 9 - Mitred bend (triangular cells)

\section{RESULTS}

The dimensions of the studied bend are :

$\mathrm{W}=0.75 \mathrm{~mm}$ ( thickness of the ribbon ).

The surface of $\Omega$ plan is: $\mathrm{S}=8 \mathrm{~mm} \times 8 \mathrm{~mm}(\mathrm{a}=\mathrm{b})$.

The permittivity of the substrate is $: \varepsilon r=10$.

The total number of cells of the plane circuit is $32 \times 32$ rectangular cells, then evidently, $64 \times 64$ triangular cells.

The treatment starts with the convergence test of the input admittance viewed by the source exciting the studied bend.

This is shown in figure 10 . We see that, it is enough, approximately 300 iterations, to ensure the convergence of the iterative method for modelling the planar bend. The real part of admittance which is null, correctly show the fact that the two extremities of the bend are in contact with the metallic box (short-rircuit) [10].

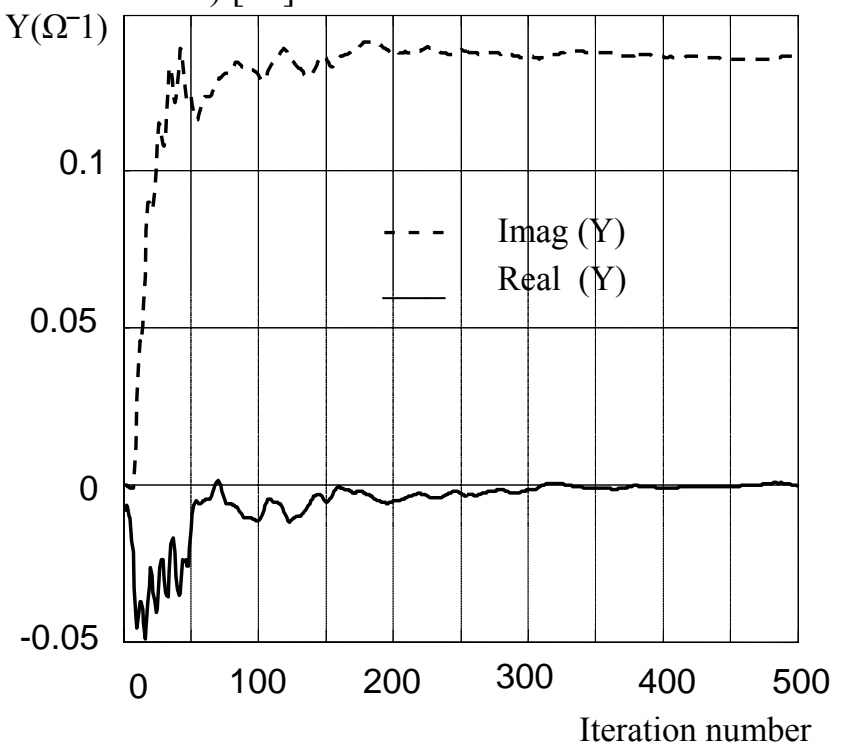

Fig. 10 - Admittance viewed by the source 
With a frequency, $\mathrm{f}=14 \mathrm{GHz}$, and for 300 iterations we have determined the current density $\mathrm{J}_{\mathrm{i}}$ of the mitred bend, which is represented in figure 11 for a plan of surface: $32 \times 32$ rectangular cells, or 64x64 triangular cells.

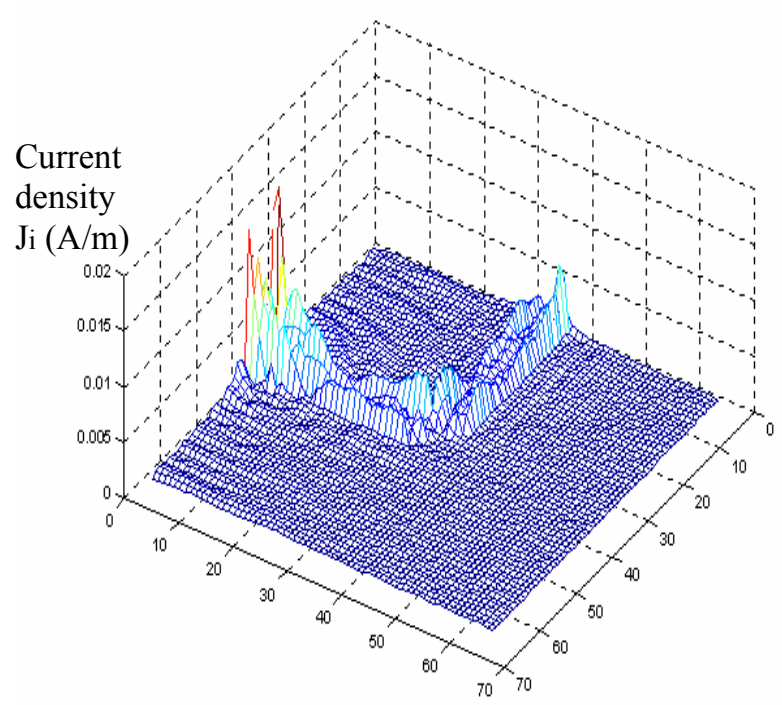

Fig. 11 - Current density Ji of the mitred bend

Finally, we have calculated the $\mathrm{S}$ parameters, particularly the reflection parameter $S_{11}$ for the three cases of planar bend: right bend (without mitre), staircase approximation mitred bend (rectangular cells), true mitred bend (triangular cells).

Figure 12 shows a comparison of the results between FMT iterative method and the method of moments.

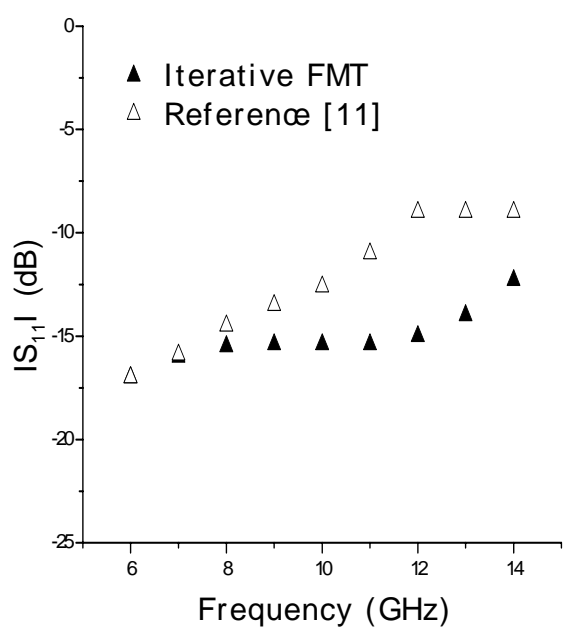

Fig. $12-S_{11}$ Parameters of the right bend

We notice a considerable variation for frequencies higher than $8 \mathrm{GHz}$ (dependent on dimensions of the planar bend).
Indeed, the right bend is very dispersive for the high frequencies, from where it's necessary to use mitred bend. In addition, towards $12 \mathrm{GHz}$ we have a resonance frequency which requires a consequent increase in the iteration number to ensure a good convergence of the method.

This same parameter is calculated for the Approximated mitred bend and the results are given in figure 13. In this case, the effect of discontinuity of the bend is reduced by the approximated mitred bend and the results are improved.

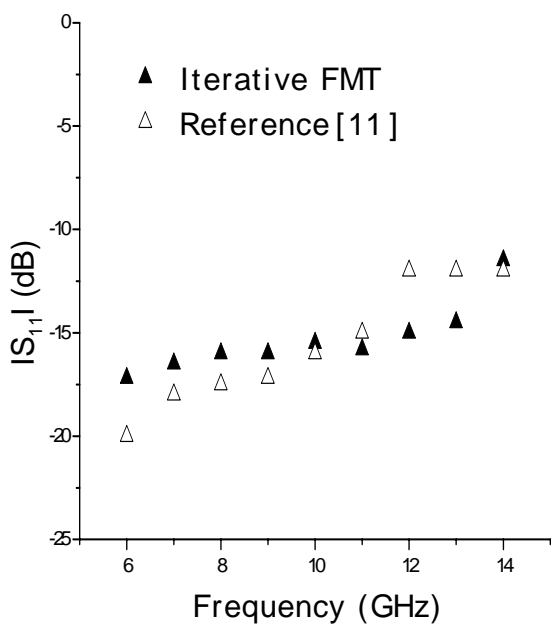

Fig. $13-S_{11}$ Parameters of the Approximated mitred bend

Lastly, the software using the triangular cells is carried out, and gives this parameter for the true mitred bend, shown in figure14. The real mitred bend, obtained by the triangular cells, gives the best results, even for the resonance frequency where the iteration number is maintained to 300 .

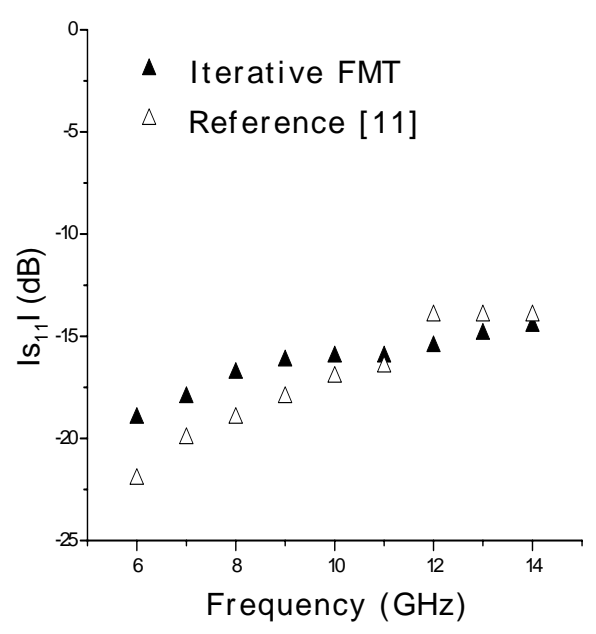

Fig. $14-S_{11}$ Parameters of the mitred bend 
We finish by doing a comparison, between the three cases of this planar bend. The figure 15 show the best transmission of the signal in the case of true mitred bend, where the reflection parameter is weaker, particularly in the $[6 \mathrm{GHz} ; 8 \mathrm{GHz}$ ).

In this band, with regard to the rectangular discretization, the triangular one gives an average attenuation of 10.3 percent for the reflection on this mitred bend.

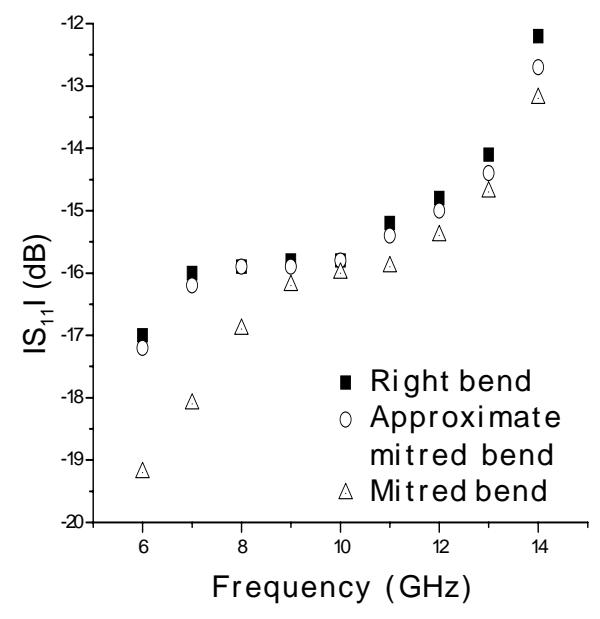

Fig. 15 - Comparison of $S_{11}$ parameter between the three cases of bend.

\section{CONCLUSION}

We described in this article, a recent method integral, namely the iterative method using a Fast Modal Transform which contributes to the numerical processing power. This new concept is exempted of the delicate choice of bases functions which exist in the other integral methods.

Our results were validated by comparison with work of R. KIPP and C H. CHAN [11]. They have used the method of moments [1]. We have showed that a judicious choice of the shape of the cells, permits to treat planar structure, such a complex is it, with very good results.

\section{REFERENCES}

[1] R.F. Harrington, Field Computation by Moment Methods. New York: Macmillan, 1968.

[2] J. R. Mosig and F. E. Gardiol, "Integral equation techniques for the dynamic analysis of microstrip discontinuities", Alta Frequenza, vol. 57, no. 5, pp. 171-181, June 1988.

[3] P. B. Katehi and N. G. Alexopoulos, "Frequency-dependent characteristics of microstrip discontinuities in millimeter-wave integrated circuits", IEEE Trans. Microwave Theory Tech., vol. MTT-33, pp. 1029-1035, Oct. 1985.

[4] H. Baudrand,"Representation by equivalent circuit of the integral methods in microwave passive elements", Eumc, Budapest, Sept.1990.

[5] M. Azizi, H. Baudrand, "A new itérative method for scattering problems", European Microwave Conf., Proc., Vol. 1, pp. 255-258, Bologne, Italy, 1995.

[6] Y. Lamhene, R. Garcia, H. Baudrand, "Modélisation d'une antenne patch par une méthode itérative basée sur le concept d'ondes", OHD99, Besançon September 1999.

[7] Y. Lamhene, A. Khoda, H. Baudrand, B. Haraoubia,"Finline Structure Characterization by the Transverse Resonance Method (T.R.M)", International Symposium on Signals Circuits and Systems (SCS'97), pp142-145, Roumania, October 1997.

[8] A. Khodja, Y. Lamhene, H. Baudrand, B. Haraoubia, "Convergence Study of Cutoff Frequencies of the Finline Structure for Different Types of Trial Function by the Transverse Resonance Method", International Conference on Computational Electromagnetics and Its Applications (ICCEA'99), Beijing, China, November 1999.

[9] P. Anders and F. Arndt, "Microstrip discontinuity capacitances and inductances for double steps, mitered bends with arbitrary angle, and asymmetric right-angle bends", IEEE Trans Microwave Theory Tech.,vol. MTT-28, pp. 1213-1217, Nov. 1980.

[10] A.A.Omar, Y.L. Chow,L.Roy and M.G.Stubbs "Effects of air-bridges and mitering on coplanar waveguide $90^{\circ}$ bends: theory and experiment", IEEE MTT-S Digest, 1993, pp. 823-826.

[11] R. Kipp and C. H. Chan, "Triangular-Domain Basis Functions for Full-Wave Analysis of Microstrip Discontinuities", IEEE Trans. Microwave Theory Tech., vol. MTT-41, no. 6/7, pp. 1187-1194, June/July 1993.

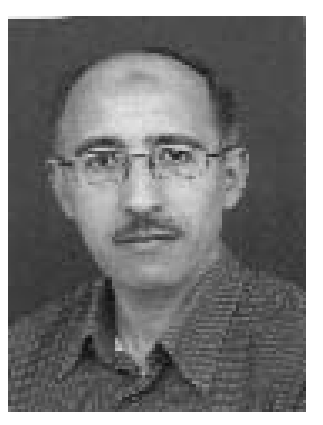

Youssef Lamhene received bachelor's degree then master's degree in Electronic, Electrotechnic and Automatic (EEA), in 1978 and 1980 from Lille University in France, and later on, in the same place, the DEA diploma in 1982 and the third cycle Doctorate diploma in Biotechnology domain in 1984. Since 1986 he teaches graduate level courses in applied electronic, 
microwave and antenna theory at the sciences and technology university of Algiers, in Algeria. His research interests are in the area of electromagnetic simulations of microwave and millimeter-wave passive components.

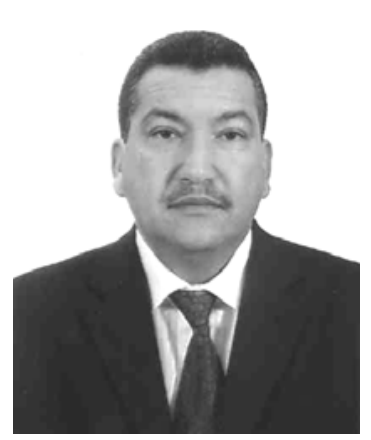

Mohamed Tellache was born in Draa El Mizane, Algeria in 1960. He received the Engineer degree in Electrical Engineering from the Ecole Nationale Polytechnique of Algiers in 1985. He received his Master degree in 1988 in electronic communication from Ottawa University, Ottawa, Canada. During 1995/1997, Mr. Tellache spent eighteen months at the laboratory of electromagnetics-Toulouse, France working principally on microwaves technology and modeling. Presently he is Assistant Professor of Electrical Engineering and Adjoin Dean at the faculty of Electronics and Computers. His present research interests focus on microwaves circuits, modeling and applied mathematics. Mr. Tellache is author and coauthor of more than 15 communications in the field.

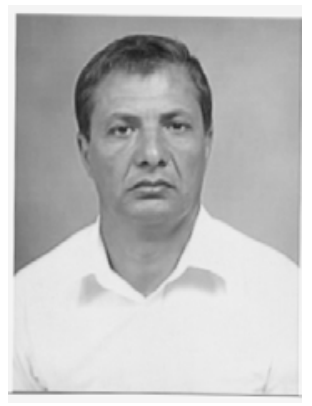

Brahim Haraoubia was born in Taoura, Algeria in 1957. He received the Engineer degree in Electrical Engineering from the Ecole Nationale Polytechnique of Algiers in 1981. He received his Master and $P h D$ degrees in 1982 and 1988 both in electronic communication from Université de Rennes, France. Presently he is full Professor of Electrical Engineering at the faculty of Electronics and Computers. His present research interests focus on microwaves circuits and modeling VHF/UHF circuits. Pr. Haraoubia is author and co-author of more than 30 publications and communications in the field and has deposit five patents in his field.

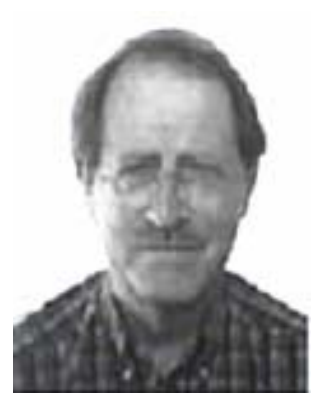

Henri Baudrand is Emeritus
Professor at ENSEEIHT,
Toulouse, France. He
specializes in modeling
passive and active circuits and
antennas. He is the author and
co-author of three books at
Cepadues edition. He has co-
authored over 100 publications
in journals and 250 contributions to international conferences. He is a follow member of IEEE society, a member of "Electromagnetism Academy" and a senior member of IEE society. He was the president of URSI, France commission B for six years (1993 to 1999) and the president of the IEEE-MTT-ED French chapter. He was awarded "officier des palmes académiques", and Director honoris causa of Lasi University. 